
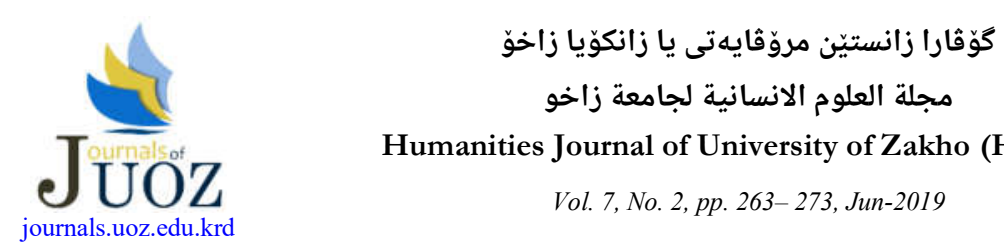

Humanities Journal of University of Zakho (HJUOZ)

Vol. 7, No. 2, pp. 263-273, Jun-2019

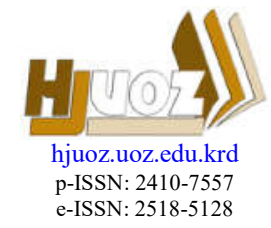

\title{
RISTEYÊN ALOZ DI KURMANCî DA
}

\author{
Mikail Bülbül \\ Mesopotamia Foundation, Diyarbakir-Turkey.
}

Received: 10. 2018 / Accepted: 03. $2019 /$ Published: 06. 2019 https://doi.org/10.26436/hjuoz.2019.7.2.478

\section{Kurte:}

Armanca vê gotarê ew e ku di kurmancî da risteyên aloz, hem ji alîyê sentaktîk hem jî semantîka wan ve bên ravekirin û tesnîfkirin. Risteyên aloz xwedî gelek curan in ku gelek caran ji hevokeka sereke û yeka nesereke yan jî hevokeka temamker pêk tên. Bi taybetî hevokên temamker ku di rewşa biresera hevoka sereke da ne, pir tên bikaranîn û hem ji alîyê sentaktîk hem jî semantîk gelek curên wan hene. Dîsa hevokên pêwendîyê ku di nava risteyekê da pêkhênên weku biker, biresera rasterast, biresera nerasterast yan jî hokerê terîf dikin, hevokên ku bi lêkerên modal, lêkerên manîpulatîf û lêkerên espektîf çêdibin jî risteyên aloz ava dikin. Herwiha hin risteyên aloz jî hene ku ji van curên navborî du an zêdetir bi hev ra tên bikaranîn û ji yên din cudatir in.

Di vê gotarê da hemû curên risteyên aloz bi awayekî berfireh bi daneyên meydanî yên ji devoka Mêrdînê û bi perspektîfeka tîpolojîk hatine vekolan.

Bêjeyên sereke: Risteyên aloz, sentaks, semantîk, hevok, devoka Mêrdînê, kurmancî.

\section{Destpêk}

Xebatên li ser sentaksa kurmancî bi giştî pir kêm in. Mijara risteyên aloz jî dîsa yek ji wan mijaran e ku kêm tişt li ser hatine nivîsîn. Tiştên hatine nivîsîn jî pir ne berfireh in û gelek cureyên risteyên aloz hene ku di wan xebatan da çêlî wan nehatiye kirin. Gotara Îbrahîm Seydo Aydogan a bi navê "Hevokên kompleks" ${ }^{1}$, ceribîneka baş e ji bo analîzkirin û tesnîfkirina risteyên aloz lê di wê da jî hin curên risteyên aloz tune ne û behsa wan nehatîye kirin. Dîsa Yaron Matras gotareka (Kurmanji Complementation: Semantic-typological Aspects In An Areal Perspektive) ${ }^{2}$ pir baş li ser semantîka hevokên temamker nivîsîye ku hevokên temamker tenê beşek in ji risteyên aloz. Herçend di gelek pirtûkên rêzimanî da bi hin sernavên cuda behsa risteyên aloz hatibe kirin jî tenê çend rûpel in û weku hat dîyarkirin ji alîyê naverokê ve, bi sînor in. Armanca vê gotarê ew e ku weku ceribînekê, risteyên aloz hem li gor rewşa wan a sentaktîk hem jî ya semantîk bên analîzkirin û tesniffkirin.

Pênasekirineka standard li ser risteyên aloz nîne. Di vê xebatê da pîvana me ya ji bo risteyeka aloz ew e ku du an zêdetir lêkerên kişandî di risteyekê da hebin, ew dibe risteya aloz. Jixwe gelek caran ew lêkerên kişandî yek a hevoka sereke ye yek jî a hevoka nesereke an jî hevoka temamker e. Risteyên aloz ên bi vî awayî weku Melissa Bowerman dibêje, ji tenzîmbûna ji nû ve (co-ordination) û ketina nav hev a hevokên sade derketine meydanê. ${ }^{3}$ Dema ku em li têkilîya hevokên ku di risteyekê da peyda dibin dinêrin, em dibînin ku gelek rewşên cuda di wan da hene. Hevokên sereke (main clause), hevokên hevseng (coordinate clause), hevokên temamker (complement clause) di van têkilîyan da ava dibin. Gelek rewşên din jî hene ku dibin sedem ku risteyek ne sade lê aloz be. Herwiha hevokên ku bi lêkerên manîpulatîf û lêkerên espektîf çêdibin jî risteyên aloz ava dikin. Herwiha hin risteyên aloz jî hene ku ji van curên navborî du an zêdetirî wan, di xwe da dihewînin û ji ên din cudatir in.

Di vê xebatê da hemû mînakên hatine dayîn ji devoka Mêrdînê ne. Du çavkanîyên van mînakan hene ku yek tekstên meydanî yên qeydkirî ne û ya din jî nivîskarê vê gotarê ye ku axêverê zikmakî yê vê devokê ye. Herwiha termînolojîya di vê xebatê da hatîye bikaranîn jî ya Weqfa Mezopotamyayê ye ku di encama gelek komxebatên zimanzanên kurd da û bi konsensuseka xurt hatiye meydanê.
Eger em ji vegerin ser mijara xwe û dest bi şeş kategorîyên ristêyên aloz bikin, em dê wan wiha dabeş bikin:

\section{Risteyên Aloz ku bi Hevokên Nesereke Ava Dibin}

Risteyên ku ji hevokeka sereke û hevokeka nesereke (subordinate cluase) pêk tên, ji alîyê binyadî ve aloz in. Di van cur risteyên aloz da bi kêmanî du hevok hene ku yek jê hevoka sereke ye û ya din jî hevoka nesereke ye û hevoka sereke ji alîyê hin rewşên semantîk ve temam dike. Hevokên nesereke di nav xwe da dabeşî van curan dibin:

\subsection{Hevokên Nesereke yên Armancî:}

Dema ku hevoka nesereke hevoka sereke ji alîyê armancê ve temam dike, ev cur risteyên aloz derdikevin holê. Bingihanekên (subordinator) weku gi/go/ki an jî ji bo gi/go/ki ne mecbûrî be jî, bi awayekî xurt tên bikaranîn. Eger em bi mînakekê îzah bikin:

(1)

Ezhatim gi te bibînim.

hevoka sereke bingihanek hevoka nesereke

Weku di mînaka jor da xuya dibe, risteya ez hatim gi te bibînim ji du hevokan pêk tê ku ez hatim hevoka sereke ye û te bibînim jî hevoka nesereke ye. Gi jî weku bingihanek hatiye bikaranîn û her du hevok gihandine hevdu. Dema em ji alîyê wateyê ve lê binêrin, em dibînin ku hevoka nesereke armanca hevoka sereke dîyar dike. Eger em hinek mînakên din bidin:

(2)

a. Bavê mi xanîk kirî gi em ji kirê xelas bibin.

b. Em li dersê xwe pir dixebitin ji bo gi ji wan derbas bibin.

Dema em li rêzbûna van hevokan dinêrin, em dibînin ku hevoka pêşîn a sereke ye û piştre jî hevoka nesereke hatiye. Di vî curê risteyên aloz da ku bi hevokên armancî çêdibin bi giştî pêşî hevoka sereke tê piştre jî a nesereke. Lê li gor rewşên semantîk, rêza wan dikare biguhere jî. Eger girîngî û cext bêtir li ser hevoka nesereke be, wê demê pêşî hevoka nesereke piştre jî hevoka sereke dikare bê û bingihaneka ji bo gi jî tê serî:

(3)

a. Ji bo gi em ji kirê xelas bibin, bavê mi xanîk kirî.

b. Ji bo gi ji dersan derbas bibin, em li wan pir dixebitin. 
Di tekstan da ku ji xebatên meydanî da hatine bidestxistin jî em li van curên risteyên aloz gelekî rast tên. Eger em hinek mînakan bidin:

(4)

a. "Me xwarina xwe, kunek du kun ava xwe, qatê nivînê xwe o gedeka xwe li devê bar kir ji bo ki em herin bajarekî din bixebitin." 4

b. "Roja dî kurê axê tê ser kahniyê go hespê xwe av bidî." "5

c. "Di vir de bi ji bo Kalê Zêwê te nebîni. "6

d. "Ez ê çime zozanan ji bo go şîr têkevê guhanê mi." 7

\subsection{Hevokên Nesereke yên Mercî:}

Dema ku hevoka nesereke hevoka sereke ji alîyê mercî ve temam dike, ev cur risteyên aloz derdikevin holê. Bingihanekên weku gi/go, eger, heg, eger gi bi awayekî obsîyonel tên bikaranîn. Ji ber ku hevokên nesereke bêtir berî hevokên sereke tên û di serê risteyê da cih digirin, riste jî bi bingihanekan dest pê dike:

$\frac{\text { Heg/gi }}{\text { bingihanek }} \quad \frac{\text { ti berî Ehmed bê, }}{\text { hevoka nesereke }} \quad \frac{\text { tê jî weri Mêrdînê. }}{\text { hevoka sereke }}$

Weku di mînaka (5)ê da xuya dibe risteya Heg tu berî Ehmed bê, tê jî weri Mêrdînê ji du hevokan pêk tê ku tê jî weri Mêrdînê hevoka sereke ye û ti berî Ehmed bê jî hevoka nesereke ye. Heg jî weku bingihanek hatiye bikaranîn û her du hevok gihandine hevdu. Dema em ji alîyê wateyê ve lê binêrin em dibînin ku hevoka nesereke merca hevoka sereke dîyar dike. Eger em hinek mînakên din bidin dê çêtir bê famkirin. (6)

a. Gi ew zilam bipeyivi, ez û hevalê xwe em nayên.

b. Heg em di wextê xwe di bixebityana, em ê niha ne di vî halî de bana.

Dema ku ev risteyên jor ku pêş̂i hevokên nesereke hatine û di serê risteyê da cih girtine û piștre jî hevokên sereke hatine, cihên wan bi hev bê guhartin jî tu problem çênabe. Lê weku meyil em dikarin bibêjin ku di risteyên aloz da ku bi hevokên mercî çêbûne, bêtir hevokên nesereke di serê risteyê da cih digirin. Eger heman risteyên aloz ên jor bi awayê ku hevokên sereke bên û li serê risteyê bên nivîsîn, dê wiha bibin:

(7)

a. Ez û hevalê xwe em nayên gi ew zilam bipeyivi.

b. Em ê niha ne di vî halî de bana heg em di wextê xwe di bixebityana.

Dema em li xebatên meydanî dinêrin, eşkere ye ku hevokên mercî gelek caran berî hevokên sereke tên. Eger em hinek mînakan ji xebatên meydanî bidin:

(8)

a. "Eger hûn bawer nakin hinek bi mi ri weri.""

b. "Gi ev şimik li nigê kê bê, lawê paşê wê wê bîni""

c. "Go ti têr bide mi ez ê mehîna xwe dime te." 10

d. "Ew fincan jî $t i$ 'd avê daki, wê'b zêr bi."

\subsection{Hevokên Nesereke yên Sedemî:}

Dema ku hevoka nesereke hevoka sereke ji alîyê sedemê ve temam dike ev cur risteyên aloz pêk tên. Bingihanekên weku $j i$ ber gi, çima gi ji bo dîyarkirina sedeman dikarin bên bikaranîn: (9)

$\begin{array}{lll}\text { Ez ji wî lawkî hez nakim } & \text { ji ber gi } & \text { pir derewa diki. } \\ \text { hevoka sereke } & \text { bingihanek } & \text { hevoka nesereke }\end{array}$

(10)

a. Ew bi mi ri napeyivi çima gi mi ew nebiryi gerê.

b. Ehmed di mektebê di jêhatî yi ji ber gi hişê xwe didi derza.
Di rewşeka normal da hevokên sereke pêşî tê piștre jî hevokên sedemî tên. Lê dema ku girîngî bêtir li ser sedemê be hevoka sedemî li pêş̂ya hevoka sereke dikare bê. Eger em heman risteyên jor bi vî awayî binivîsin dê bingihanek bên serî piştre hevokên sedemî û piştre jî hevokên sereke bên:

(11)

a. Çima gi mi ew nebiryi gerê ew bi mi ri napeyivi.

b. Ji ber gi hişê xwe didi derza Ehmed di mektebê di jêhatî yi.

Di xebatên meydanî da herçend zêdebûna hevokên nesereke yên armancî û mercî balê dikişinin jî, hevokên nesereke yên sedemî li gor wan gelekî kêm in. Eger em çend mînakan ji xebatên meydanî bidin dê baştir bibe:

(12)

a. "Ji ber ku te ez li pişt berî dîtim, ev bû mêrga min."12

b. "Ji ber gi haya ahlê Gola Gulê jê heyi gi Dêrikiyayê erîş̂̂ ser wan biki, dikevi pêşiyê." 13

c. "Em newêrîbû êdî veketa ji ber gi zilamekî gelekîxwirt bû."

\section{Risteyên Aloz ku bi Hevokên Temamker Ava Dibin}

Hevokên temamker (complement clause) ew hevok in ku pêkhêneka risteyê ji alîyê wateyê ve temam dikin. Michael Noonan ji bo hevokên temamker dibêje, dema ku pêveberek (predicate) çi di rola bikerê de, çi jî di rola bireserê da dibe, eger argumenta pêvebereka din be, ew dibe temamker ${ }^{15}$. Cudahî di navbera hevokên sereke da heye û lazim e neyên tevlihevkirin. Lewra hevokên nesereke hevoka sereke temam dike lê hevokên temamker pêkhênekê ji risteyekê temam dikin ango terîf dikin. Bi gotineka din mirov bibêje, di risteyên aloz de, ku ji du hevokan pêk tê û yek hevoka sereke û yek jî nesereke ye, risteyek risteyekê temam dike lê di risteyên aloz ên bi hevokên temamker de, risteyên temamker tenê pêkhêneka risteyê terîf ango modîfîye dike. Eger em li mînaka jêr binêrin dê baştir bê famkirin:

(13)

Ez dibînim gi gelek kes nehatini.

hevoka sereke bingihanek hevoka temamker

Di risteya (13)an da hevoka gelek kes nehatini hevoka ez dibînim temam dike û di fonksîyona bireserê da ye. Yanî hevoka temamker biresera hevoka sereke ye. Bingihaneka gi/go (ku/ko) jî em dibînin ku hem di hevokên nesereke da hem jî di hevokên temamker da tê bikaranîn. Ji ber ku di gelek rol û erkan da tê bikaranîn, Yaron Matras gi/go/kuyê weku bingihaneka giștî (general subordinator) bi nav dike. ${ }^{16}$ Hevokên temamker cur bi cur in û her dem ne di wê rewşa mînaka jorîn da ne. Dema em bi giştî li hevokên temamker binêrin, em dikarin wan wisa dabeş bikin:

\subsection{Hevokên Temamker ên Lêkerên PPVyê:}

Lêkerên pêhisînê (perception) yên weku dîtin û bihîstinê ku em bi alîkarîya endamên weku çav û guh wan dihesînin; lêkerên pêzanînê (cognition) yên weku zanîn, fêm kirin û texmîn kirinê ku encama fealîyeta mekanîzmaya fikirînê ne û bi zanînê ve têkildar in; û lêkera vegotinê (utterance) gotin dema ku piştî xwe hevokeka temamker distînin, risteyên aloz derdixin holể ${ }^{17}$. Hevokên ku bi van lêkeran çêdibin bi awayekî semantîk di rola bireserê da ne. Loma ew jî di kategorîya hevokên temamker da cih digirin. Eger ji bo ku rola wan a bireserî em fam bikin mînakekê bidin dê bêtir zelal bibe:

Me fêm kir gi ew zilam derewa diki.

Di risteya (14)an da me fêm kir risteya sereke û ew zilam derewa diki jî hevoka temamker e û hem weku semantîk hem jî weku sentaktîk di rola bireserê da ye. Mirov li ser risteyeka wiha bifikire dê baştir bê famkirin: Me tiştek fam kir. Di vê risteyê da çawa ku eşkere ye bêjeya tiştek di rola bireserê da ye, 
di risteya me fêm kir gi ew zilam derewa diki da jî hevoka temamker ew zilam derewa diki di rola bireserê da ye. Lewra tiştek teqabûlî hevoka ew zilam derewa diki ye. Yanî me tişstek fam kir û ew tişt jî derewkirina wî̀ zilamî ye. Em dikarin van cur hevokan ku di forma bireserekê da ne, bikin sê beş:

\subsubsection{Lêkerên Pêhisînê (perception verbs):}

Lêkerên weku dîtin û bihîstinê bi hesta hisînê ve têkildar in û dema ku piştî xwe hevokeka temamker distînin, risteyên aloz pêk tînin ku ew hevokên temamker di rola bireserê da ne. Bingihaneka " $g i$ "yê dîsa bi awayekî obsîyonel tê bikaranîn:

\section{Ez dibînim gi Ehmed diheri malê.}

Di vê risteya jor da hevoka Ehmed diheri malê hevoka temamker e û di rola bireserê da ye. Yanî ez tiştekî dibînim û ew tişt jî çûna Ehmed ya malê ye. Eger em hinek mînakên din bidin dê zelaltir bibe:

(16)

a. Mi bihîstiyi gi cîranê me bar kiriyi.

b. Zilam pê hisiya gi tiştê xerab çêbûni.

Dema ku di hevoka temamker da bêjeyên pirsîyarîyê yên weku "kî, kîjan, çawa, çima"yê hebin, li şûna bingihaneka giyê bi giranî bê tê bikaranîn. Eger em heman risteyan bi awayê pirsîyarî binivîsin dê wiha bibin:

(17)

a. Mi nebihîstiyi bê, kîjan cîranê me bar kiriyi.

b. Zilam pê hisiya bê, çima tiştê xerab çêbûni.

c. We bi çavê serê xwe dît bê, ew zarok çiqasî digrî.

Di xebatên meydanî da jî lêkerên dîtin û bihîstinê weku du lêkerên pêhisînî bi bikaranîna xwe ya zêde balê dikişinin. Bi taybetî jî lêkera dîtinê zêde tê bikaranîn:

a. "Dibînin go wa ya çend zilamên biçek û xencer tên."18

b. "Mi dî Hecî Ahmed Axa bang kir." 19

c. "His kir ${ }^{20}$ go wê jinbava wê çêleka zer gurênî, zahf ber çêlekê ket." 21

d. "Sê jinê Usifê Hesen Paşa bihîstin gi Gijol çûyi qasidê Mencolê." 22

\subsubsection{Lêkerên Pêzanînê (cognition verbs):}

Lêkerên weku zanîn, fam kirin, texmîn kirin, bawer kirin, jibîr kirin, ferq kirin, guman kirin ku têkildarî mekanîzmayên zanîna mirovan e, dema ku piştî xwe hevokeka temamker distînin ew jî risteyên aloz pêk tînin û di rola bireserê da ne. Di nava lêkerên PPVyê da kategorîya herî berfireh a van cur lêkeran e û mînakên wê pir in:

(19)

a. Ez zanim gi Hesen xanîk kiriyi.

b. Ez bawer dikim rokê em ê jî azad bibin.

Dema em li xebatên meydanî dinêrin em dibînin ku lêkera pêzanînî gelekî tên bikaranîn. Bi taybetî lêkerên zanîn $\hat{u}$ fêm kirinê pir tên bikaranîn:

(20)

a. "Yadê te çilo zanibû gi ez weku Hatim ne başim û ne çavfire mi." 23

b. "Ma ti nizanî go ev mêrg a min a?" 24

c. "Li ser vê peyvê Şewlê Biçûk fềm diki gi bavê wî heyi."

d. "Mi fềm kir ki her tişt bi dilê jina min i." "26

Lê ji bilî lêkerên zanîn û fêm kirinê gelek lêkerên din jî bi heman awayî tên bikaranîn û dikevin nav lêkerên pêzanînî. Di mînakên jêr da lêkerên texmîn kirin, bal dayîn, tê derxistin, ji bîr kirin, dêhn dayin, goman kirin jî lêkerên pêzanînî ne û piștî xwe hevokên temamker stendine:

(21)

a. "Wê texmîn nekir ki ew ê wê bikuji."27

b. "Mi bala xwe dayê gi ew şikeft qehfê serê insanekî ye."28

c. "Me ji bîra kirya go em bidnê." 29

d. "Dêhna xwe dayê go qulek wa di wê dera ha da ya."

e. "Yanî ewî goman nedikir go dido bên."

\subsubsection{Lêkera Vegotinê (utterance):}

Dema ku di nava risteyekê da axaftina hin kesan cih bigire û ew axaftin di forma risteyê da be, ew riste jî dibe aloz û êdî ne sade ye. Kesê veguhêz ${ }^{32}$ yanê axêver dikare wan axaftinên ku ne yê wî ne, bi du awayan veguhêze; veguhastina rasterast û veguhastina nerasterast. Di her du rewşan da jî hevokên hatine veguhastin, ji alîyê rola rêzimanî ve bireserên rasterast in. Weku mînak dema em bibêjin: Hesen got, ez nayêm. hevoka ez nayêm biresera rasterast e. Ji ber ku em dizanin lêkera gotinê têper e û mirov tiştekî dibêje û di risteyeka weku ya jor da $e z$ nayêm teqabulî wî tiştê ku hatiye gotin e. Weku me got veguhastinên kesên din dikarin bi du awayan bên gotin:

\subsubsection{Veguhastina Rasterast:}

Di veguhastina rasterast da dema ku gotina kesên din tê veguhastin kesên din ew gotin bi çi awayî gotibin kesê veguhêz wê gotinê bi heman awayî dibêje û guhartinê tê da çênake:

(22)

a. Ehmed ji mi ri go "Ez sibê nayêm."

b. Dema ku em li hev rast hatin got "Çima hûn nehatine?"

c. Wê got "Min pir bêriya Ehmed kiriye."

Di metnên meydanî da mînakên vê yekê pir zêde ne. Em dikarin gelek mînakan ji xebatên meydanî bidin:

(23)

a. "Îsa ji me re go, "Gelî zaroyê Şatihiya, bi Xwedê ez nema karim wî berdim $\hat{u}$ xwe jê biqetînim. "33

b. "Heso ji xwe ra got, "Bi Xwedê îsev ew kûçikê Biro nehatiye ber rezê xwe." 34

c. "Vê jî lê vegerand go: "Yadêe! Ez ê çi biki j"lawê xelkê $y i$ ?" 35

\subsubsection{Veguhastina Nerasterast:}

Dema ku gotin û axaftin ji alîyê veguhêz ve bi awayekî nerasterast vediguhêze, êdî veguhêz bi peyvên xwe, wê guhastinê dike û hinek guhartin di wan axaftinan da çêdibe ku bi awayekî nerasterast tên guhastin. Herwiha bingihaneka kuyê ji bo van bikaranînên nerasterast tê bikaranîn ${ }^{36}$. Eger axaftina ku tê veguhastin pirsîyarî be, ji dêvla $k u$ yê $b e ̂$ tê bikaranîn. Eger em mînak (22.a)yê bi awayê veguhastina nerasterast bibêjin dê wiha bibe:

(24)

a. Ehmed ji mi ri go "Ez sibê nayêm."

b. Ehmed ji mi ri go ku ew sibê nayê.

Di veguhastinên nerasterast da ji ber ku mealen tê gotin û şîroveya veguhêz dikeve nav risteyên bi vî rengî, dibe ku tiştê hatiye gotin û tiştê hatiye veguhastin ji hev hinekî cuda bin. Di axaftina rojane da hema hema hemû veguhastinên kesên din ên rasterast in û veguhastinên nerasterast pir kêm in.

\subsection{Hevokên Temamker ên Lêkerên Modal:}

Bikaranîna lêkerên modal risteyeka sade dike risteyeka aloz. Di wan risteyan da ku lêkerên modal di wan da hene bi awayekî nerasterast du hevok hene ku yek hevoka sereke ya din jî hevoka temamker e. Weku mînak dema em dibêjin: ez karim nên bixwim em dikarin bibêjin ku du hevok di vê risteyê da hene ku ez karim hevoka sereke û ez nên bixwim jî hevoka 
temamker e. Di risteyeka wiha da hevoka temamker bi awayekî semantîk teqabûlî bireserê ye. Yanî dema em dibêjin ez karim em dizanin ku karîn lêkereka têper e û bireserekê dikare bistîne. Di risteyeka weku ya jor da jî ez nên bixwim teqabûlî bireserê ye. Ji ber ku ez tiştekî karim û ew jî xwarina nanî ye û xwarina nanî jî teqabûlî bireserê ye. Ji ber ku hevokên temamker di pozîsyona bireserê da ne, dişibe hevokên temamker ên kategorîya lêkerên PPVyê jî. Givon ${ }^{37}$ jixwe hevokên bi vî awayî weku analojîya bireserê dibîne. Ji bo ku kombînasyona her du hevokan baş bê famkirin, em dikarin mînakeka din bidin:

(25)

a. Ehmed dixwazi. (Risteya sereke ye.)

b. Ehmed diheri malê. (Risteya temamker e.)

c. Ehmed dixwazi heri malê. (Kombînasyona du hevokan e.)

(26)

a. Ez karim. (Risteya sereke ye.)

b. Ez di carkê di çar hêka dixwim. (Risteya temamker e.)

c. Ez karim di carkê di çar hêka bixwim. (Kombînasyona du hevokan e.)

Di xebatên meydanî da em rastî gelek bikaranînên lêkerên modal ên weku xwestin, karîn, wêrînê tên ku bi taybetî zêdebûna lêkera karînê balê dikişîne:

(27)

a. "Ji bo çi tu nikari kîrgokî tenê teva karê xwe bîni." "38

b. "Yek jî tu dixwazê bikevê nav xezîne û malê mi." 39

c. "Heso newêrîbû jê biştexile." 40

d. "Ez nikarim bid ser ahda xwe." 41

\subsection{Hevokên Temamker ên Lêkerên Manîpulatîf:}

Di kurmancî da çawa ku kausatîfî (causative) bi rêya lêkerên kausatîf û bi alîkarîya lêkera danê çêdibe, bi rêya lêkerên manîpulatîf (manipulative verbs) ên weku kirin, hiştin /hêlan û xwestinê jî çêdibe. Ev lêker jî dema ku piştî xwe hevokekê distînin, ew hevok teqabulî bireserê ye. Bêguman ev lêkerên ku me behs kirin ne ku fonksîyona wan a bingehîn wiha ye lê ew dikarin weku lêkereka manîpulatîf jî bên bikaranîn. Weku mînak dema em dibêjin: min gelek tişt kirin lêkera kirinê di wateya xwe ya bingehîn da hatiye bikaranîn. Lê dema ku em bibêjin: min kir ku Ehmed biçe malê lêkera kirinê di fonksîyona manîpulatîf da ye û hevoka Ehmed biçe male jî hevokeka temamker e ku teqabulî rola bireserê ye. Yanî min tiştek kiriye û ew tişt jî teqabulî çûna Ehmed ya malê ye. Loma jî lêkerên manîpulatîf piştî xwe dema ku hevokekê distînin ew hevok di rola bireserê da ye. Ji ber ku lêkera kirinê di nav lêkerên manîpulatîf da ya herî berbelav e û zêde tê bikaranîn, em dikarin pêşî mînakan ji bo kirinê bidin û mijarê bêtir zelal bikin: (28)

a. Mi kir gi Elî sêvê bixwi.

b. Hesen kiribû gi gundî paleyê bikin.

c. Ehmed kir gi zarok xwarinê zû xelas bikin.

Di van risteyan da ku lêkera kirinê bi awayekî manîpulatîf hatiye bikaranîn, du pêkhênên sereke hene ku yek jê manîpuleker (manipulator) e ya din jî manîpuleber (manipulee) e û manîpuleker tevgera manîpuleberê manîpule dike. Eger ji risteya jorîn Hesen kiribû gi gundî paleyê bikin, mînakan bidin, Hesen manîpuleker e û gundî jî manîpuleber e. Yanî Hesen karê ku gundî dikin manîpule dike. Lêkera kirinê ne tenê di zimanê kurdî da lê di gelek zimanên dinyayê da jî, di çêkirina kausatîfîyê da tê bikaranîn. Di zimanên weku romanî, îngilîzî, koreyî, tamîlî, teleguyî, îndonezî, jakalteyî, yûnanîya nû, tayî û gelekên din da jî lêkera kirinê vê fonksîyonê dibîne. ${ }^{42}$ Givon jî ji bo prototîpa semantîk a lêkerên manîpulatîf vana rêz dike: ${ }^{43}$ a. Bikera lêkera sereke tevgera manîpuleber manîpule dike, weku bikereka potansîyel.

b. Manîpulebera lêkera sereke bi bikera lêkera temamkerê da hevreferant $\mathrm{e}$.

c. Hevoka temamker bûyera armanckirî ku ji alîyê manîpuleberê ve tê kirin, kod dike.

Ji bo ku lêkerên manîpulatîf û sîntaksa wan baş bê famkirin em pêşî pêkhên û fonksîyonên wan binavbikin dê çêtir bê famkirin. Weku mînak di risteya "Hesen kiribû gi gundî paleyê bikin." de:

Hesen: manîpuleker e.

kiribû: lêkera sereke ye.

gundî: manîpuleber e.

paleyê bikin: lêkera hevoka temamker e.

Givon ji bo prototîpa sentaktîk a lêkerên manîpulatîf jî gelek taybetîyan rêz dike lê em dikarin bibêjin ku hinek ji wan li tîpolojîya kurdî nayên. Qismek jî li tîpolojîya kurdî dikin ku em dikarin bibêjin ku yên sereke û li tîpolojîya kurmancî tên ev in:

a. Manîpulekera/bikera lêkera sereke, bikera hevoka sereke ye. b. Manîpulebera lêkera sereke, yan biresera rasterast yan jî biresera nerasterast a hevoka sereke ye.

c. Manîpulebera lêkera sereke di heman demê da bikera hevoka temamker e.

Weku mînak eger em dîsa ji risteyeka weku "Hesen kiribû gi gundî paleyê bikin." Mînakê bidin em dê bibêjin ku Hesen manîpulekera/ajana hevoka sereke ye û gundî jî manîpuleber e ji ber ku ji alîye manîpulekerekî ve tê manîpulekirin. Jixwe encama manîpulekirina Hesen a gundîyan jî ew e ku gundî paleyê dikin. Rewşa hevoka temamker jî weku semantîk di pozîsyona bireserê da ye. Ji alîyê semantîka karê ku tê kirin em binêrin, em dikarin bibêjin ku gundî bixwe herçend tên manîpulekirin jî ji ber ku karekî dikin di heman demê da biker e jî. Gillian Catriona Ramchand ji bo bikerên (anku kara) bi vî rengî têgeha bikera navgînî a navbeynkar (instrumental intermediate agent) bi kar tîne. ${ }^{44}$

Lazim e mirov vê yekê jî bibêje ku rewşa sentaktîk a lêkerên manîpulatîf herçend weku hev bin jî rewşa wan a semantîk dikarin ji hev cuda bin. Weku mînak lêkera hiştin ${ }^{45}$ dema di forma manîpulatîf da tê bikaranîn têkilîya di navbera manîpuleker û manîpuleber ne weku a lêkera kirinê ye. Lewra manîpuleber bêtir xwedî îrade ye û tesîra manîpuleker a li ser wê, ne zêde xurt e.

(29)

a. Min hişt gi Elî sêvê bixwi.

b. Ehmed dihêli gi zarok xwarinê zû xelas bikin.

Lêkerên weku misade kirin, yesaq kirin, rica kirin jî dîsa di formeka manîpulatîf da dikarin bên bikaranîn. Eger em ji bo heman mînakê wan bi kar bînin dê wiha bin:

(30)

a. Min misade kir gi Elî sêvê bixwi.

b. Min yesaq kir gi Elî sêvê bixwi.

c. Min rica kir gi Elî sêvê bixwi.

Dema em li xebatên meydanî dinêrin em dibînin ku gelek mînakên lêkerên manîpulatîf hatine bikaranîn û bi taybetî zêdebûna bikaranîna lêkera hiştin/hêlanê pir balê dikişîne:

(31)

a. "Bûrînya xwe ji şêx xwestin gi şêx wa efûkê."46

b. "E nahêlim go bigihê vî kurkî." 47

c. "Te nedihişt $e z$ ê din jî bidim wan." 48

d. "Dixwazim go hûn werin." 49 


\section{Risteyên Aloz ku bi Hevokên Hevseng Ava Dibin}

Dema ku du an zêdetir bûyerên ku bi hev ve negirêdayî ne û serbixwe ne, di risteyekê da bên bikaranîn, ev cur risteyên aloz çêdibin. Yanî du an zêdetir hevokên hevseng (serbixwe) di yek risteyê da bên bikaranîn; ew riste dibe aloz. Gelek caran gihanekên weku $\hat{u}$, lê, ne ... ne, ya ...ya dikevin navbera hevokên hevseng. Lê bikaranîna van gihanekan ne şert e û bêyî wan jî dibe. Weku mînak dema em risteyeka weku bavê mi nan xwar lê xweha mi nexwar bibêjin em dikarin bibêjin ku du hevokên hevseng di vê risteyê da hene ku yek jê bavê mi nan xwar a din jî xweha mi nan nexwar e. Herçend lê weku gihanek hatiye bikaranîn jî, bikaranîna wê obsîyonel e û eger neyê bikaranîn jî ne şaş e. Em hinek mînakên din bidin da ku zelaltir bibe:

(32)

a. Ez çûm lê ew nehat.

b. Mi dixwar, Ehmed jî dipeyivî.

c. Bavê wê li wir ma, ew bixwe jî çû.

Di xebatên meydanî da jî em rastî gelek risteyên aloz tên ku ji du an zêdetir hevokên hevseng pêk tên. Eger em mînakan ji van xebatan bidin:

(33)

a. "Ijja wê çaxê Rustemê Zal, Silêmanê Sindî kuştiye $\hat{u}$ heyfa kalikê xwe hilaniye $\hat{u}$ hatiye. " 50

b. "Hema her wa ye tewlêde yi û her ji xwe ri vek, bib $\hat{u}$ her. " ${ }^{51}$ c. "Xatûn gora xwe danî, hirbya xwe ji serê xwe kir, qirka xwe jê ri vekir pê ri xwarin xwar, pê ri rûnişt, pê ri peyivî.",52

d. "Keçikê keja xwe rist $\hat{u}$ bada, li nav milê xwe kir û çû mal. "53

Risteyên aloz ên ku ji du an zêdetir hevokên hevseng pêk tên bi gihanekên weku ya ... ya, ne ...ne jî dikarin çêbibin. Eger em ji metnên meydanî mînakan bidin:

(34)

a. "Ya tê mi jî bikujî $\hat{u}$ ya ez ê heyfa kalikê xwe hilînim." ${ }_{54}$

b. "Ya tê sitirîkê mi dê ya jî tê heft nan û qursikkê dê mi." "55

c. "Ne xulam hat, ne mehîn hat $\hat{u}$ ne keça wî hat."

d. "Bi ti kesî ne bistêna $\hat{u}$ ne bida." 57

Hevokên hevseng ji bilî van rewşan carinan dikare di forma hevokên navberî (paranthetical) da jî çêbibin. Hevokên navberî dema tiştek tê gotin ew hevok ne ku agahîyê li ser wî tiştî dide. Weku mînak dema em bibêjin: Ehmed -kurê meta Elî ye - do hatibû mala me em hevoka navberî bi kar tînin.

\section{Hevokên Pêwendîyê (relative clause)}

Hevokên pêwendîyê di nava risteyekê da pêkhêneka risteyê modîfîye dikin. Ew pêkhên dibe ku ji alîyê rolên rêzimanî ve biker, bireser an jî hoker be. Hevokên pêwendîyê dibe ku gelek curên bêjeyan modîfiye bikin. Lê tiştê girîng ew e ku hevokên pêwendîyê risteya ku tê da cih digire, wê dike risteyeka aloz. Dîsa bingihaneka gi/go/kuyê bi awayekî obsîyonel tê bikaranîn. Hevokên pêwendîyê dikarin gelek curên pêkhênên risteyekê modîfîye bikin:

\subsection{Dema ku bikerê modîfîye dikin:}

Hevokên pêwendîyê dema ku di nava risteyê da navdêrekê modîfîye dikin ku ew navdêr di rola bikerê da be, dibe modîfiyekera bikerê. Hevokên pêwendîyê ji alîyê sentaktîk her dem paşnavdêrî ne (postnominal) û piştî navdêran tên. Em li mînakên jêrîn binêrin mesele baştir tê famkirin: (35)

a. Hevalê gi do ez li sûkê dîtibûm, çûyi.

b. Hesenê pir nan dixwar, ne zêde birçî bû.
Di mînaka (35.a)yê da do ez li sûkê dîtibûm hevoka pêwendîyê ye û bikerê yanî peyva heval modîfiye dike. Dîsa $g i$ weku bingihanek hatiye bikaranîn. Di xebatên meydanî da gelek mînak ji hevokên pêwendîyê peyda dibin ku bikerê modîfiye dikin. Em dikarin gelek mînakan ji bo vê yekê bidin:

(36)
a. "Ê gi hat kustin jî, -wî bê heqî- bavê wî kuştibû." "58
b. "Ev keçika gi ez dibêjim, li nigê vêya dixi."
c. "Hevalê wî go pevre diçune hêzinga, saxlam bû." "60

\subsection{Dema ku biresera rasterast modifîye dikin:}

Hevokên pêwendîyê dema ku navdêrekê modîfìye dikin û ew navdêr jî di rola biresera rasterast da be, hevoka pêwendîyê terîfa biresera rasterast dike. Eger bi mînakan îzah bikin:

a. Bavê wî, zilamê gi hatibû mala me nas nekir.

b. Me birê te yî ji Stenbolê hatibû, nedîtibû.

Di mînaka (37.a)yê da hatibû mala me hevoka pêwendîyê ye û bireserê yanî peyva zilam modîfîye dike. Di xebatên meydanî da mînakên modîfîyekirina bireserê gelekî kêmtir in li gor bikerê.

(38)

a. "Ew siwarê go vêga li wê derê ya ti dibênê?"61

b. "Werîsê go ji dest wa ketî bêhemdî wa bi xwe ve şidand." 62

\section{3. Dema ku bireserên nerasterast modifîye dikin:}

Hevokên pêwendîyê bireserên nerasterast jî modîfîye dikin ku bireserên nerasterast li gor rola xwe ya semantîk dabeşî gelek curan dibin. Eger em li gor rewşa semantîk a bireserên nerasterast hevokên pêwendîyê kategorîze bikin dê wiha bên dabeşkirin:

\subsubsection{Yên ku Biresera Nerasterast a Navgînî Modîfîye Dikin:}

Biresera navgînî ya nerasterast (instrumental indirect object), navgîna ku kar pê tê kirin nîşan dide. Dema ku hevokên pêwendîyê navdêra ku biresera navgînî nîşan dide modîfîye dike, hevoka pêwendîyê terîfa pêkhêna navgînî dike. Eger em bi çend mînakan zelal bikin:

(39)

a. Qesab bi kêra gi devê wê ko bû goşt jê dikir.

b. Em bi qemyona gi nih kirîbûn, çûn bajêr.

Di mînaka (39.a)yê da devê wê ko bû hevoka pêwendîyê ye û biresera navgînî yanî peyva kêrê modîfîye dike.

\subsubsection{Yên ku Biresera Nerasterast a Cihî Modîfîye Dikin:}

Bêjeyên ku cihî anku mekanê didin nasîn, dema ku weku bireserên nerasterast ên cihî tên bikaranîn û hevokên pêwendîyê jî wan bêjeyan modîfîye dikin, hevokên pêwendîyê terîfa wê bireserê dikin. Herçend ji bo rola rêzimanî a van bêjeyên ku cihî dîyar dikin, di gelek xebatan da weku hoker hatibe gotin jî Talmy Givon wan weku biresera nerasterast a cihî (locative indirect object) dibîne. ${ }^{63}$ Eger em mînakan bidin: (40)

a. Em li mala gi do şewitîbû û tişt tê de nemabû, digerîyan.

b. Herî zêde zarok li welatê gi şer lê diqewimi dimrin.

Em dikarin gelek mînakan ji xebatên meydanî jî bidin:

(41)

a. "Gehane cihê go tê da ketibû bajarê mara." 64

b. "Ez ê berê wî dime walatê go jê hew vegerî, riya hate nehatê." 65

c. "Çû gundê go anî edresa wî tê de yazkirî." 
5.3.3. Yên ku Biresera Nerasterast a Datîf Modîfîye Dikin: Biresera nerasterast a datîf (dative indirect object) di lêkerên dutêper da gelek caran wergira (receiver) biresera rasterast e. Weku mînak dema em dibêjin mi qelem da Ehmed biresera rasterast qelem e û Ehmed jî dibe wergira wê. Lêkera dayînê lêkereka dutêper e û piştî xwe biresera nerasterast a datîf digire: (42)

a. Wan gelek kitêb dan zarokê gi ji bajarên xwe derketibûn.

b. Perê xwe giş dabûn zilamê gi perê geleka xwaribû.

\subsubsection{Yên ku Hokerên Demê Modîfîye Dikin:}

Dema ku hevokên pêwendîyê navdêrên ku demê vedibêjin modîfîye dikin ku ew jî di rola hokerî da bin, hevokên pêwendîyê hokerên demê terîf dikin. Bêjeyên weku wext, sal, roj gelek caran weku navdêr tên bikaranîn ku hevokên pêwendîyê wan modîfiye dikin:

(43)

a. Mamoste sala gi em ne li vir bûn qeze derbas kiribû.

b. Ehmed wexta gi zarok bû carekê hatibû.

Di xebatên meydanî yên herêma Mêrdînê da mînakên hevokên pêwendîyê ku bêjeyeka demî modîfîye dikin pir zêde xuya dibin. Em dikarin gelek mînakan ji van xebatan bidin:

(44)

a. "Roja Hatim çû rehmetê birayê wi ban diya xwe kir." 67

b. "Wexta kû zewiciye hatiye Serê Avê." 68

c. "Wextê go diçin, Zeynika Zêrin dibê ez ê jî êm." 69

\section{Risteyên Aloz ên bi Lêkerên Espektîf}

Di kurmancî da hin lêker hene ku her çiqas di eslê xwe da, ne lêkerên espektîf û modal bin jî, di hinek bikaranînan da dikarin ji bo rolên espektîf û modal bên bikaranîn. Talmy Givon dema ku behsa tîpolojîya semantîk a lêkerên modalîteyî dike ${ }^{70}$, destpêkirin (inception), bidawîhûn (termination), dewamdarî (continuation) serkeftin (success) û sernekeftinê (failure) weku modalîteya espektîf û teşebus (attempt), nîyet (intent), zerûrîyet (obligation) an şîyanê (ability) jî weku modal dihesibîne. Ew jî bi bikaranîna hin lêkerên weku rabûn, lêxistin, kirin û çûnê pêk tê ku ev lêkerên navborî bi lêkerên bingehîn da tên bikaranîn û wateyên espektîf ava dikin. Yanî dema ku lêkereka espektîf û lêkereka bingehîn di yek risteyê da bên bikaranîn, ew riste jî ji alîyê binyada xwe ve aloz e. Ev lêkerên ku em behsa wan dikin weku yên modal karîn, wêrîn an jî vîyanê hevokên ku di pozîsyona bireserê da ne, nastînin. Loma ev lêkerên weku rabûn, çûn, lêxistinê û kirinê kategorîyeka din in û cuda ne.

Weku me got lêkerên rabûn, lêxistin û çûnê jî di hinek rewşan da ne di wateya xwe ya bingehîn da lê bi lêkereka din da tên bikaranîn û wê rola espektîf û modal bi cih tînin. Weku mînak dema em dibêjin: mi rabû got lêkera rabûnê ne di wateya xwe ya bingehîn a ferhengî da ye û lê ji bo rola modal hatiye bikaranîn. Lewra wateya helwesta teşebuskirinê tê da heye û helwesta teşebusê jî rewşeka modal e. Eger em van lêkerên ku rolên espektîf û modal bi cih tînin li gor rewşa wan a espektîf û modal polîn bikin, em dikarin wan wiha polîn bikin:

\subsection{Lêkera Çûnê ya Espekta Bidawîbûnê (terminative} aspect):

Lêkera çûnê dema ku di demên borî da tê bikaranîn, wateya espektîf li lêkera bingehîn zêde dike û bidawîbûn (terminative) anku temambûna lêkera bingehîn bi me dide zanîn. Ji bo ku baştir bê famkirin eger mînakekê û konteksa wê bidin:

(45)

a. Kontekst: Xwarinê nexwe, em dê bi hev da bixwin. b. Mi çû xwar. (Edî dereng e, karê xwarinê bi dawî bû lewra mi xwar)
Em dikarin hinek mînakên din jî bidin ku mijar bêtir zelal bibe. Lêkera çûnê di serê hevokê da jî û piştî bikerê jî dikare bê bikaranîn:

(46)

a. Çû mi her tişt ji wî ri got.

b. Ehmed çû di wê dersê di mayi.

c. Çû bavê wî çelek firot.

Weku di mînaka jor da jî xuya dibe, çû xelasbûn anku bidawîbûna karekî nîșan dide. Di bikaranîna lêkera çûnê da carinan zahmet e ku em fam bikin gelo çûn di wateya xwe ya esasî da an jî di wateya espektîf da hatiye bikaranîn. Lê dema em li xebatên meydanî dinêrin, ji ber ku kontekst dîyar e, em dizanin ku di kîjan wateyê da hatiye bikaranîn. Di mînakên jêr da jî ji konteksê dîyar bûne ku ew lêker di fonksîyoneka espektîf da hatine bikaranîn:

(47)

a. "Çû hew şitexalî ji devê wî derket."71

b. "Wele $\hat{u}$ çû nav lepê Mele reviya." 72

c. "Çû ew cil ji xwe kirin." "73

d. "Êvarî çû j'bave xwe r' go." "74

\subsection{Lêkerên Rabûn û Lêxistinê yên Espekta Teşebusê:}

Lêkerên rabûn û lêxistinê hem wateyeka espektîf hem jî ji ber ku helwestekê dîyar dikin, wateyeka modal li karê ku tê kirin zêde dikin. Alîyê wê yê espektîf ew e ku destpêkirinekê nîşan dide û alîyê wê yê modal jî ew e ku helwesta biryardarîyê û teşebusekê (attempt) îfade dike. Yanî hem destpêkirinek heye û hem jî di wê destpêkirinê da biryardarîyek û îradeyek ku teşebusê dike heye. Eger em weku mînak li ser risteya: mi xwar û mi rabû xwar bifikirin em dikarin cudahîya di navbera wan da baştir zelal bikin. Dema em dibêjin mi xwar em tu agahîyekê li ser rewş û helwesta xwarinê jê nikarin derxin. Lê dema em dibêjin $m i$ rabû xwar em fam dikin ku karê xwarinê piştî pêvajoyekê bi cih hatiye û di paşxaneya wê da îradeyek anku biryardarîyek, teşebusek heye û li ser wê bingehê dest pê kiriye. Dema ku di demên borî da tên bikaranîn em dizanin ku ew wateya destpêkirinê ku encama biryardarî anku teşebusê ye, bi cih hatiye û temam (perfective) e. Em dikarin pêşî bi lêkera rabûnê dest pê bikin û bi hinek mînakên din zelaltir bikin:

(48)

a. Min rabû xwar.

(Min-bi biryardarî teşebus kir /dest pê kir û- xwar.)

b. Ehmed rabû kevir avêtê.

(Ehmed -bi biryardarî teşebus kir /dest pê kir û- kevir avêtê.)

c. Me rabû xanî ji bo wî lêkir.

(Me ji bo wî -biryar da, teşebus kir, dest pê kir - xanî lêkir.)

Di xebatên meydanî da em dikarin bi sedan mînakên bikaranîna espektîf a lêkera rabûnê peyda bikin. Di metnên meydanî da tiştekî din ê ku bala mirovan dikişîne heye ku ew jî bikaranîna lêkera rabûnê a di serê risteyê da ye. Dema ku jêbirina (deletion) bikerê pêk hatibe jî pêk nehatibe jî lêkera rabûnê dîsa jî dikare di serê risteyê da bê bikaranîn:

(49)
a. "Rabû zuhêlik çerm ji paşs serê wî rakir." "75
c. "Rabû Reşo hat cem Xidir Çelebî."
d. "Rabû em darbasî cem wî bûn." 77
e. "Rabû bi şopa wî̀ ket." 78

Bikaranîna lêkera lêxistinê jî wateyeka espektîf û modal li karê ku tê kirin zêde dike, lê piçekî cudatir e ji lêkera rabûnê. Ji ber ku lêkera lêxistinê jî biryardarî û teşebusekê îfade dike lê cudahîya wê ew e ku di lêxistinê da wateya bilezûbezbûnê anku zûbûnê heye. Weku mînak dema em bibêjin: wan lêxistin çûn em dizanin ku li gor ew rabûn çûn cudatir e û dema em lêxistinê bi kar tînin wateya ew nesekinîn, hema biryar dan $\hat{u}$ dest pê 
kirin /teşebus kirin $\hat{u}$ çûn em dikarin jê derxin. Jixwe ji xebatên meydanî jî xuya ye ku gelek caran bi lêkerên mîna hatin û çûnê da tê bikaranîn ku tevgereka fîzîkî di wan da heye. Lazim e vêya jî bê gotin ku li herêma Tor Abîdîn ji dêvla lêxistinê di heman wate û fonksîyonê da lêkera lêdanê tê bikaranîn: (50)
a. "Lêxist ê wê hey ew çû."79
b. "Hûtê gewr lê da çû."
c. "Lêda çû Hesarê gundkî wilo."

\subsection{Lêkera Kirinê ya Espekta Nêzîkbûnê (proximate} aspect)

Espekta nêzîkbûnê bi alîkarîya lêkera kirinê çêdibe. Lêkera kirinê bi lêkera eslî ya risteyê ra tê bikaranîn û wateya nêzîkbûna bicihanîn an jî bicihneanîna wî karî dide. Lêkera kirinê di vê fonksîyonê da ji bilî dema dahatî di hemû deman da mirov dikare bi kar bîne. Çawa ku di dema niha da wateya hindik maye li lêkera bingehîn zêde dike di demên borî da jî dema ku tê bikaranîn wateya hindik mabû li lêkera eslî zêde dike. Weku mînak dema ku em dibêjin: ez dikim herim lêkera kirinê nêzîkbûna biencambûna wî karî bi me dide zanîn:

a. Ehmed diki mala xwe bar biki.

b. Ez dikra biketma teşqela wan, lê xalê mi nehişt.

\section{Risteyên Aloz ku bi Gelek Curên Hevokan Ava Dibin}

Heta niha me çend curên risteyên aloz dîtin ku ji hevokên sereke û yên nesereke, hevokên sereke û yên temamker an jî ji hevokên hevseng pêk dihatin. Herwiha hat famkirin ku her yek ji wan jî dabeşî curên din jî dibin. Risteyên aloz ji bilî van hemû curan dibe ku ji du yan zêdetir ev curên navborî hatibin ba hev û bi vî awayî pêk hatibin. Yanî du curên van hevokan dikarin bên ba hev û risteyên aloz pêk bên. Weku mînak dema em dibêjin: hevalê gi do me dîtib̂े nayê em dizanin ku hevoka pêwendîyê (relative clause) hatiye bikaranîn û loma jî ev riste aloz e. Baş e eger me bigota: hevalê gi do me dîtibû nayê eger pir dereng be dê çawa bibûya? Em dizanin ku di vê risteya aloz da hem hevoka pêwendîyê heye hem jî hevoka mercî heye. Yanî dibe ku risteyên aloz ji du yan bêtir hevokan pêk bên ku her yek ji wan curên wan ji hev cuda ne. Dema em li xebatên meydanî jî dinêrin, em dibînin ku gelek curên hevokan bi hev da jî tên bikaranîn û risteyan hîn aloztir derkevin holê. Bi taybetî dema ku riste dirêj dibin îhtîmala ku gelek curên hevokan di wan da peyda bibin jî zêde dibe:

(52)

a. "Şivan şîr dohtibû $\hat{u}$ pişkul dixistine navê go bixwê." "82

- Di risteya jor da hem du hevokên hevseng hem hevoka mercî hatiye bikaranîn.

b. "Rabûn wa eskerê qral gotnê go, "Ti tê were, ti nayê ji emê te bizorê bin." 83

- Di risteya jor da hem lêkera espektîf rabûn hatiye bikaranîn hem jî hevoka ku veguhastina rasterast îfade dike, hatiye bikaranîn.

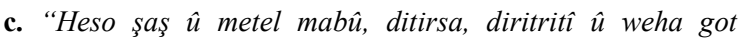
"Şêxşêban, ez bi qurbano! Lingê xwe hilgêve da bi erdê ve nexiriqin." 84

- Di risteya jor da hem çend hevokên hevseng hene hem jî dîsa lêkera vegotinê hatiye bikaranîn ku veguhastina rasterast tê da heye.

Divê em ji bîr nekin ku bi awayekî teorîk bêsînor curbicur hevok dibe ku bi hev ra bên bikaranîn û kombînasyonên gelekî cudatir jî bên çêkirin. Lê mebest li vir ew e ku em bizanin ku ji duyan zêdetir curên hevokan jî gelek caran dikarin bên bikaranîn û ev yek jî tîpolojîyeka cuda ye.

\section{Encam}

Di vê xebatê da ku ceribînek bû ji bo analîzkirin û tesnîfkirina risteyên aloz, li gor rewşa wan a sentaktîk û semantîk behsa șeş curan hat kirin ku her yek ji wan jî xwedî hinek binbeşên din in. Bi taybetî risteyên aloz ên ku ji hevokeka sereke û hevokeka temamker (complement clause) pêk tên xwedî gelek binbeşan in. Mirov dikare çend xalên kurt û sereke yên li ser risteyên aloz wisa rêz bike:

1. Risteyên aloz ku ji hevokeka sereke û yeka nesereke pêk tên li gor rewşên semantîk weku armancî, mercî û sedemî rêz dibin û bi berfirehî tên bikaranîn.

2. Hevokên temamker ku pêkhêneka risteyê terîf dikin yan jî gelek caran analojîya bireserê ne û şûna wê digirin, kategorîya herî berfireh in ku hevokên lêkerên PPVyê, hevokên lêkerên modal û hevokên lêkerên manîpulatîf dikevin navê.

3. Hevokên pêwendîyê ku gelek caran biresera rasterast an jî nerasterast terîf anko modîfîye dikin, hevokên aloz pêk tînin û ew jî bi awayekî berfireh tên bikaranîn.

4. Risteyên aloz ku ji du yan zêdetir hevokên hevseng pêk tên bi gihanekên weku lê, $\hat{u}$, ne ... ne, ya ... ya bi hev ve tên girêdan û ew jî kategorîyeka cuda ne.

5. Lêkerên weku rabûn, çûn, lêxistin ê û kirinê ji bilî rol û wateyên xwe yên ferhengî, di rolên espektîf da jî tên bikaranîn û risteyên aloz ava dikin.

6. Risteyên aloz dema ku ji du yan zêdetir van curên hevokên navborî pêk tên, dibin kategorîyeka din ku bi taybetî di risteyên dirêj da dibe ku zêdetir peyda bibin.

\section{Ferhengok:}

aspekta nêzîkbûnê aspekta bidawîbûnê bingihanek

bireser

hevok

hevoka hevseng

hevoka nesereke

hevoka sereke

hevokên navberî

lêker

manîpulatîf

manîpuleber

manîpuleker

pêhisîn

pêveber

pêzanîn

riste

vegotin

wergir

\author{
: proximate aspect \\ : terminative aspect \\ : subordinator \\ : object \\ : clause \\ : coordinate clause \\ : subordinate clause \\ : main clause \\ : paranthetical clause \\ : verb \\ : manipulative \\ : manipulee \\ : manipulator \\ : perception \\ : predicate \\ : cognition \\ : sentence \\ : utterance \\ : receiver
}

\section{9. Çavkanî û referans}

\section{1. Çavkanî:}

Akbaş, Mehmet Şerif. Di Devoka Qoserê De Rêjeya Bikaranina Dengan, Projeya Lîsansa Bilind a Bêtez, Zanîngeha Mardîn Artukluyê, Enstîtuya Zimanên Zindî yên Li Tirkiyeyê, Şaxa Makezanista Ziman û Çanda Kurdî, Mêrdîn. 2013

Akıncı, Enes. Bikaranîna Rengêran Di devoka Kerboranê De (Weku Mînak Du çîrokên Herêma Kerboranê), Projeya Lîsansa Bilind a Bêtez, Zanîngeha Mardîn Artukluyê, Enstîtuya Zimanên Zindî yên Li Tirkiyeyê, Şaxa Makezanista Ziman û Çanda Kurdî, Mêrdîn. 2014

Altunışık, Elif. Cihêtîyên Kişandina Lêkeran Li Herêma Torê. Projeya Lîsansa Bilind a Bêtez, Zanîngeha Mardîn Artukluyê Enstîtuya Zimanên Zindî yên Li Tirkiyeyê Şaxa Makezanista Ziman û Çanda Kurdî, Mêrdîn. 2015

Arslan Aydın, Gulçin. Rêjeya Bikaranîna Dengan Di Herêma Torê de, Projeya Lîsansa Bilind a Bêtez, Zanîngeha Mardîn Artukluyê, Enstîtuya Zimanên Zindî yên Li Tirkiyeyê, Şaxa Makezanista Ziman û Çanda Kurdî, Mêrdîn. 2013 
Atıș, Ali. Di Devoka Çiyayê Mazî de Bikaranîna Hevalnavan, Projeya Lîsansa Bilind a Bêtez, Zanîngeha Mardîn Artukluyê, Enstîtuya Zimanên Zindî yên Li Tirkiyeyê, Şaxa Makezanista Ziman û Çanda Kurdî, Mêrdîn. 2016

Aydogan, Îbrahîm Seydo. Guman-1, Demnasî, Hevoksazî, Watesazî û Gotar, Weşanên Lîs, Ankara. 2013

Ayta, Ramazan. Çîrok û Çîrçîrokên Kaniya Xezalan, Projeya Lîsansa Bilind a Bêtez, Zanîngeha Mardîn Artukluyê, Enstîtuya Zimanên Zindî yên Li Tirkiyeyê, Şaxa Makezanista Ziman û Çanda Kurdî, Mêrdîn. 2013

Baki, Selman. Bikaranîna Pêşgir $\hat{u}$ Paşgirên Kurmancî Di Dêrika Çiyayê Mazî de -Wek Mînak Du Çîrokên Herêma Dêrikê, Projeya Lîsansa Bilind a Bêtez, Zanîngeha Mardîn Artukluyê, Enstîtuya Zimanên Zindî yên Li Tirkiyeyê, Şaxa Makezanista Ziman û Çanda Kurdî, Mêrdîn. 2013

Barlas, Ceylan. Bikaranîna Rengdêran Di Devoka Qoserê (Mêrdîn) De, Projeya Lîsansa Bilind a Bêtez, Zanîngeha Mardîn Artukluyê, Enstîtuya Zimanên Zindî yên Li Tirkiyeyê, Şaxa Makezanista Ziman û Çanda Kurdî, Mêrdîn. 2013

Baş, Abdulhekim. Rêjaya Bikaranîna Dengan Di Devoka Qoserê De, Projeya Lîsansa Bilind a Bêtez, Zanîngeha Mardîn Artukluyê, Enstîtuya Zimanên Zindî yên Li Tirkiyeyê, Şaxa Makezanista Ziman û Çanda Kurdî, Mêrdîn. 2013

Bilgiç, Behiye, Rêjeya Bikaranîna Dengan Di Devoka Tor Abîdin De, (Wek Mînak Şeşe Çîrokên Herêma Tor Abîdîn), Projeya Lîsansa Bilind a Bêtez, Zanîngeha Mardîn Artukluyê, Enstîtuya Zimanên Zindî yên Li Tirkiyeyê, Şaxa Makezanista Ziman û Çanda Kurdî, Mêrdîn. 2014

Bowerman, Melissa. The acquisition of complex sentences. in Studies in language acquisition, Cambridge University Press, 1979. (r. 285-305)

Bulgan, Bilal. Bikaranîna Hevalnavan (Rengdêran) $D i$ Devoka Herêma Kercewsê De Projeya Lîsansa Bilind a Bêtez, Zanîngeha Mardîn Artukluyê, Enstîtuya Zimanên Zindî yên Li Tirkiyeyê, Şaxa Makezanista Ziman û Çanda Kurdî, Mêrdîn. 2013

Çoban, Mehmet. Bikaranîna Rengdêran Li Herêma Midyadê, Projeya Lîsansa Bilind a Bêtez, Zanîngeha Mardîn Artukluyê, Enstîtuya Zimanên Zindî yên Li Tirkiyeyê, Şaxa Makezanista Ziman û Çanda Kurdî, Mêrdîn. 2014

Demirkaya, İslameddin. (2014), Di Nava Eşîra Morîkan De Rêjeya Zayenda Bêjeyan, Projeya Lîsansa Bilind a Bêtez, Zanîngeha Mardîn Artukluyê, Enstîtuya Zimanên Zindî yên Li Tirkiyeyê, Saxa Makezanissta Ziman û Canda Kurdî, Mêrdîn. Derin, İpek. Frekansa Tîpê Kurdî Devoka Nisêbînê da (Mêrdîn)-Rêjeya Bikaranîna Dengan, Projeya Lîsansa Bilind a Bêtez, Zanîngeha Mardîn Artukluyê, Enstîtuya Zimanên Zindî yên Li Tirkiyeyê, Şaxa Makezanista Ziman û Çanda Kurdî, Mêrdîn. 2013

Givón, Talmy. Syntax, An Introduction, Volume I, John Benjamins Publishing Company,Amsterdam/Philadelphia. 2001

Givón, Talmy. Syntax, An Introduction, Volume II, John Benjamins Publishing Company, Amsterdam/Philadelphia. 2001

Güler, Şehmus. Efsaneyên Li Ser Mêrdînê, Projeya Lîsansa Bilind a Bêtez, Zanîngeha Mardîn Artukluyê, Enstîtuya Zimanên Zindî yên Li Tirkiyeyê, Şaxa Makezanista Ziman û Çanda Kurdî, Mêrdîn.

Güneş, Mehmet Bakır. (2013), Rêjeya Bikartanîna Dengan Di Devoka Tor Abdîn De Projeya Lîsansa Bilind a Bêtez, Zanîngeha Mardîn Artukluyê, Enstîtuya Zimanên Zindî yên Li Tirkiyeyê, Şaxa Makezanista Ziman û Çanda Kurdî, Mêrdîn. 2013

İbrahimoğlu, Şoreș. Bikaranîna Lêkeran Ji Alîyê Binyadî Ve Li Herêma Qoser Û Tûr Abdîn (Li ser Çar Çîrokên Herêma Qoser $\hat{u}$ Tûr Abdîn), Teza Xelaskirinê ya Lîsansê, Zanîngeha Mardîn Artukluyê, Fakulteya Edebiyatê- Beşa Ziman û Edebiyata Kurdî, Mêrdîn. 2013
Îldem, Abdulkadîr. Dengbêj Mihemedê Xursî. Projeya Lîsansa Bilind a Bêtez, Zanîngeha Mardîn Artukluyê, Enstîtuya Zimanên Zindî yên Li Tirkiyeyê, Şaxa Makezanista Ziman û Çanda Kurdî, Mêrdîn. 2013

Kaya, Mahsum. Rêjeya Bikaranina Dengan Di Devoka Tor Abidîn de. Projeya Lîsansa Bilind a Bêtez, Zanîngeha Mardîn Artukluyê, Enstîtuya Zimanên Zindî yên Li Tirkiyeyê, Şaxa Makezanista Ziman û Çanda Kurdî, Mêrdîn. 2013

Koşar, Fikret. Bikaranîna Rengdêran di Çîrokên Devoka Qoserê (Mêrdînê) de.Projeya Lîsansa Bilind a Bêtez, Zanîngeha Mardîn Artukluyê Enstîtuya Zimanên Zindî yên Li Tirkiyeyê Şaxa Makezanista Ziman û Çanda Kurdî, Mêrdîn. 2014.

Matras, Yaron. Kurmanji Complementation: Semantictypological Aspects In An Areal Perspektive, in Sprachtypol Univ. Forsch. (STUF), Berlin, 2002. h. 55. (r. 49-63)

Moreno, Carlos Juan. Make and the semantic origins of causativity: a typological study. In Causatives And Transitivity, Editor: B. Comrie \&Polinsky, Amstersdam, 1993. (r. 155-164)

Noonan, Michael. Complementation, in Shopen, Timothy (Ed.), Language Typology and Syntactic Description, c. 2., Complex Constructions. Cambridge University Press, 1985. (r. 52-150)

Ramchand, Gillian Catriona. Verb Meaning and the Lexicon, A First-Phase Syntax, Cambridge University Press, Cambridge. 2008

Şimşek, Ahmet. Rêjeya Bikaranîna Dengan Di Devoka Kercosê De (Weku mînak Şeş Çîrokên Herêma Kercosê, Projeya Lîsansa Bilind a Bêtez, Zanîngeha Mardîn Artukluyê, Enstîtuya Zimanên Zindî yên Li Tirkiyeyê, Şaxa Makezanista Ziman û Çanda Kurdî, Mêrdîn. 2013

\subsection{Referans:}

1. Aydogan, Îbrahîm Seydo. Guman-1, Demnasî, Hevoksazî, Watesazî û Gotar, Weşanên Lîs, Ankara. 2013. (r. 119-160)

2. Matras, Yaron. Kurmanji Complementation: Semantictypological Aspects In An Areal Perspektive, in Sprachtypol Univ. Forsch. (STUF), Berlin, h. 55. 2002. (r. 49-63)

3. Bowerman, Melissa. The acquisition of complex sentences. in Studies in language acquisition, Cambridge University Press, 1979. r. 285.

4. Atış, Ali. Di Devoka Çiyayê Mazî de Bikaranîna Hevalnavan, Projeya Lîsansa Bilind a Bêtez, Zanîngeha Mardîn Artukluyê, Enstîtuya Zimanên Zindî yên Li Tirkiyeyê Şaxa Makezanista Ziman û Çanda Kurdî, Mêrdîn, 2016. r. 13.

5. Bulgan, Bilal. Bikaranîna Hevalnavan (Rengdêran) Di Devoka Herêma Kercewsê De, Projeya Lîsansa Bilind a Bêtez, Zanîngeha Mardîn Artukluyê, Enstîtuya Zimanên Zindî yên Li Tirkiyeyê, Şaxa Makezanista Ziman û Çanda Kurdî, Mêrdîn. 2013. r. 17.

6. Koşar, Fikret. Bikaranîna Rengdêran di Çîrokên Devoka Qoserê (Mêrdînê) de, Projeya Lîsansa Bilind a Bêtez, Zanîngeha Mardîn Artukluyê, Enstîtuya Zimanên Zindî yên Li Tirkiyeyê, Şaxa Makezanista Ziman û Çanda Kurdî, Mêrdîn. 2014. r.16.

7. Bilgiç, Behiye. Rêjeya Bikaranîna Dengan Di Devoka Tor Abîdîn De, (Wek Mînak Şeş Çîrokên Herêma Tor Abîdîn), Projeya Lîsansa Bilind a Bêtez, Zanîngeha Mardîn Artukluyê, Enstîtuya Zimanên Zindî yên Li Tirkiyeyê, Şaxa Makezanista Ziman û Çanda Kurdî, Mêrdîn. 2014. r. 22.

8. Atış, h.b., r. 25.

9. Demirkaya, İslameddin. Di Nava Eşîra Morîkan De Rêjeya Zayenda Bêjeyan, Projeya Lîsansa Bilind a Bêtez, 
Zanîngeha Mardîn Artukluyê, Enstîtuya Zimanên Zindî yên Li Tirkiyeyê, Şaxa Makezanista Ziman û Çanda Kurdî, Mêrdîn. 2014. r. 8 .

10. Bilgiç, h.b., r. 15.

11. Akbaş, Mehmet Şerif. Di Devoka Qoserê De Rêjeya Bikaranîna Dengan, Projeya Lîsansa Bilind a Bêtez, Zanîngeha Mardîn Artukluyê Enstîtuya Zimanên Zindî yên Li Tirkiyeyê Şaxa Makezanista Ziman û Çanda Kurdî, Mêrdîn. 2013. r. 11. 12. Şimşek, Ahmet. Rêjeya Bikaranîna Dengan Di Devoka Kercosê De(Wek mînak Şeş Çîrokên Herêma Kercosê, Projeya Lîsansa Bilind a Bêtez, Zanîngeha Mardîn Artukluyê, Enstîtuya Zimanên Zindî yên Li Tirkiyeyê Şaxa Makezanista Ziman û Çanda Kurdî, Mêrdîn, 2013. r. 10.

13. Atış, h.b., r. 11.

14. Atış, h.b., r. 13.

15. Noonan, Michael. Complementation, in Shopen, Timothy (Ed.), Language Typology and Syntactic Description, c. 2., Complex Constructions. Cambridge University Press, 1985. r. 52

16. Matras, Yaron. Kurmanji Complementation: Semantictypological Aspects In An Areal Perspektive, in Sprachtypol Univ. Forsch. (STUF), Berlin, 2002. r. 51.

17. Ji bo lêkerên pêhisinn, pêzanîn û vegotinê êdî em dê bibêjin PPV. Jixwe di Îngilîzî da jî PCU tê gotin ku kurteya bêjeyên "perception", "cognition" û "utterance"ê ye.

18. Çoban, Mehmet. Bikaranîna Rengdêran Li Herêma Midyadê, Projeya Lîsansa Bilind a Bêtez, Zanîngeha Mardîn Artukluyê, Enstîtuya Zimanên Zindî yên Li Tirkiyeyê Şaxa Makezanista Ziman û Çanda Kurdî, Mêrdîn, 2014. r. 16.

19. Saruhan, Murat. Bikaranîna Daçekan Li Herêma Mêrdînê (Wek Mînak Şeş Çîroka Hecî Ahmed Axa Û Reşo Kûrî, Projeya Lîsansa Bilind a Bêtez, Zanîngeha Mardîn Artukluyê, Enstîtuya Zimanên Zindî yên Li Tirkiyeyê Şaxa Makezanista Ziman û Çanda Kurdî, Mêrdîn, 2013. r. 17.

20. Ji dêvla lêkera bihîstinê Li Herêma Tor Abîdîn hiskirin tê bikaranîn.

21. Bulgan, h.b., 16.

22. Barlas, h.b., 20.

23. Barlas, h.b., 18.

24. Şimşek, h.b., r. 9.

25. Atış, h.b., 7.

26. Atış, h.b., 14.

27. Atış, h.b., 17.

28. Koșar, h.b., 18.

29. Kaya, h.b.,19.

30. Bilgiç, h.b., 20.

31. Bulgan, h.b., 11.

32. Veguhêz: aktaran, aktarıcı

33. Saruhan, h.b., 16.

34. Altunışık, Elif. Cihêtîyên Kişandina Lêkeran Li Herêma Torê. Projeya Lîsansa Bilind a Bêtez, Zanîngeha Mardîn Artukluyê Enstîtuya Zimanên Zindî yên Li Tirkiyeyê Şaxa Makezanista Ziman û Çanda Kurdî, Mêrdîn. 2015. r. 8.

35. Baş, h.b., r. 13.

36. Aydogan, h.b., r.144.

37. Givón, Talmy. Syntax, An Introduction, Volume II, John Benjamins Publishing Company, Amsterdam/Philadelphia. 2001. r. 55

38. Baki, Selman. Bikaranîna Pêşgir û Paşgirên Kurmancî Di Dêrika Çiyayê Mazî de -Wek Mînak Du Çîrokên Herêma Dêrikê, Projeya Lîsansa Bilind a Bêtez, Zanîngeha Mardîn
Artukluyê, Enstîtuya Zimanên Zindî yên Li Tirkiyeyê, Şaxa Makezanista Ziman û Çanda Kurdî, Mêrdîn. 2013, r. 18.

39. Çoban, h.b., 20.

40. Altunışık, h.b., 8 .

41. Akbaş, h.b., 23.

42. Moreno, Carlos Juan. Make and the semantic origins of causativity: a typological study. In Causatives And

Transitivity, Editor: B. Comrie \&Polinsky, Amstersdam, 1993. r. 155

43. Givón, h.b., c.2., r. 41.

44. Ramchand, Gillian Catriona. Verb Meaning and the Lexicon, A First-Phase Syntax, Cambridge University Press, Cambridge, 2008. r. 163.

45. Li herêma Mêrdînê lêkera hişstinê di dema niha û dahatiyê da nayê bikaranîn û li şûna wê lêkera hêlanê tê bikaranîn.

46. Güler, Şehmus. Efsaneyên Li Ser Mêrdînê, Projeya Lîsansa Bilind a Bêtez, Zanîngeha Mardîn Artukluyê, Enstîtuya Zimanên Zindî yên Li Tirkiyeyê, Şaxa Makezanista Ziman û Çanda Kurdî, Mêrdîn, r. 8.

47. Kaya, h.b.,21.

48. Barlas, h.b., 18.

49. Derin, h.b., r. 5 .

50. Koşar, h.b., 19.

51. İldem, Abdulkadîr. Dengbêj Mihemedê Xursî. Projeya Lîsansa Bilind a Bêtez, Zanîngeha Mardîn Artukluyê Enstîtuya Zimanên Zindî yên Li Tirkiyeyê, Şaxa Makezanista Ziman û Çanda Kurdî, Mêrdîn, 2013. r.17.

52. Barlas, h.b., 19.

53. Güneş, Mehmet Bakır. Rêjeya Bikartanîna Dengan Di Devoka Tor Abdîn De Projeya Lîsansa Bilind a Bêtez, Zanîngeha Mardîn Artukluyê, Enstîtuya Zimanên Zindî yên Li Tirkiyeyê, Şaxa Makezanista Ziman û Çanda Kurdî, Mêrdîn. 2013. r. 9.

54. Koșar, h.b., 19.

55. Bilgiç, h.b., 20.

56. Bulgan, h.b., 11.

57. Arslan, Aydın Gulçin. Rêjeya Bikaranîna Dengan Di Herêma Torê de, Projeya Lîsansa Bilind a Bêtez, Zanîngeha Mardîn Artukluyê, Enstîtuya Zimanên Zindî yên Li Tirkiyeyê, Şaxa Makezanista Ziman û Çanda Kurdî, Mêrdîn. 2013. r. 13 58. Baş, Abdulhekim. Rêjaya Bikaranîna Dengan Di Devoka Qoserê De, Projeya Lîsansa Bilind a Bêtez, Zanîngeha Mardîn Artukluyê, Enstîtuya Zimanên Zindî yên Li Tirkiyeyê Şaxa Makezanista Ziman û Çanda Kurdî, Mêrdîn, 2013. r. 21.

59. Demirkaya, h.b., r. 7-8.

60. Bulgan, h.b., r. 19.

61. Bulgan, h.b., r. 14.

62. Bilgiç, h.b., 20.

63. Givón, Talmy, Syntax, An Introduction, Volume I, John Benjamins Publishing Company, Amsterdam/Philadelphia. 2001. r.137.

64. Bulgan, h.b., 23.

65. Bulgan, h.b., 10.

66. Kaya, Mahsum. Rêjeya Bikaranîna Dengan Di Devoka Tor Abidin de. Projeya Lîsansa Bilind a Bêtez, Zanîngeha Mardîn Artukluyê, Enstîtuya Zimanên Zindî yên Li Tirkiyeyê, Şaxa Makezanista Ziman û Çanda Kurdî, Mêrdîn. 2013, r. 24. 67. Barlas, Ceylan. Bikaranîna Rengdêran Di Devoka Qoserê (Mêrdîn) De, Projeya Lîsansa Bilind a Bêtez, Zanîngeha Mardîn Artukluyê, Enstîtuya Zimanên Zindî yên Li 
Tirkiyeyê, Şaxa Makezanista Ziman û Çanda Kurdî, Mêrdîn. 2013, r. 18

68. Derin, İpek. Frekansa Tîpê Kurdî Devoka Nisêbînê da (Mêrdîn), Projeya Lîsansa Bilind a Bêtez, Zanîngeha Mardîn Artukluyê, Enstîtuya Zimanên Zindî yên Li Tirkiyeyê Şaxa Makezanista Ziman û Çanda Kurdî, Mêrdîn 2014. r. 2.

69. Bulgan, h.b., 17.

70. Givón, h.b., c. 2. r.55.

71. Bulgan, h.b., r. 22.

72. Baş, h.b., r. 11.

73. Akınc1, Enes. Bikaranîna Rengêran Di devoka Kerboranê De (Weke Mînak Du çîrokên Herêma Kerboranê), Projeya Lîsansa Bilind a Bêtez, Zanîngeha Mardîn Artukluyê, Enstîtuya Zimanên Zindî yên Li Tirkiyeyê Şaxa Makezanista Ziman û Çanda Kurdî, Mêrdîn, 2004. r. 23.

74. Akbaş, h.b., r. 19.
75. İbrahimoğlu, Şoreş, Bikaranîna Lêkeran Ji Alîyê Binyadî Ve Li Herêma Qoser Û Tûr Abîdîn (Li ser Çar Çîrokên Herêma Qoser û Tûr Abîdin), Teza Xelaskirinê ya Lîsansê, Zanîngeha Mardîn Artukluyê, Fakulteya Edebiyatê - Beşa Ziman û Edebiyata Kurdî, 2015. r. 17.

76. Saruhan, h.b., 15.

77. Saruhan, h.b., 17.

78. Ayta, Ramazan. 2013, Çîrok $\hat{u}$ Çîrçîrokên Kaniya Xezalan, Projeya Lîsansa Bilind a Bêtez, Zanîngeha Mardîn Artukluyê, Enstîtuya Zimanên Zindî yên Li Tirkiyeyê, Şaxa Makezanista Ziman û Çanda Kurdî, Mêrdîn. r. 14

79. Saruhan, h.b., 18.

80. Altunışık, h.b., 11.

81. Bulgan, h.b., 12.

82. Bilgiç, h.b., 20.

83. Bulgan, h.b., 23.

84. Altunışık, h.b., 8 . 


\section{The Complex Sentences in Kurmanji}

\section{Abstract:}

This study deals with the analysis and classification of complex sentences in terms of both syntactical and semantical features. There are many kinds of the complex sentences and they frequently consist of a main clause and a subordinate clause or a complement clause. Especially the complement clauses which are at the object position of the the main clauses are used widely and vary widely both syntactically and semantically. In addition, the complex sentences can be constituted by the relative clauses which modify a constituent such as a subject, object or an indirect object in a clause; the modal, manipulative verbs's clauses and aspective verbs. However, there are complex sentences which are separated and include two or more different types of clauses mentioned above.

In this paper all sorts of the complex sentences are comprehensively researched according to data based on Mardin's accent from the typological point of view.

Keywords: Complex sentences, syntax, semantic, clause, Mardin's accent, kurmanji.

تتناول هذه الدراسة تحليل وتصنيف الجمل المعقدة من حيث الخصائص النحوية والسلالية في الكورمانجية

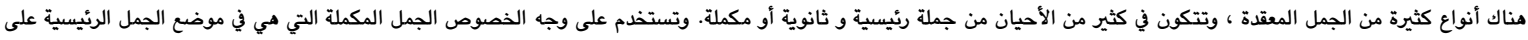

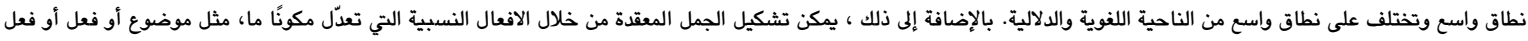

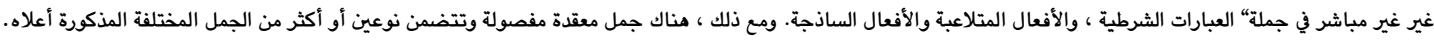

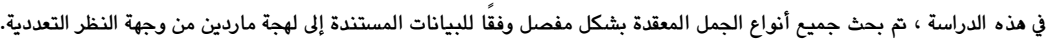

الكلمات الدالة: الجمل المعدة، تكوين الجمل، لهجة، لهجة ميردين، الكورمانجية. 